\title{
GSM Based Industrial Appliances Control Using Arduino Processor
}

\author{
V. Yadesh ${ }^{1}$, K. Venkatachalam ${ }^{2}$ \\ 1PG Student, Department of ECE, Velalar College of Engineering \& Technology, Thindal, Erode \\ ${ }^{2}$ Professor, Department of ECE, Velalar College of Engineering \& Tech., Thindal, Erode
}

\begin{abstract}
In the modern society most of the devices are controlled by the remote control system. Because,in such working person may not be available to control the appliances or device manually. For an example, nuclear reactor industry and hazardous chemical gas industry are rarely used manual control system. So user can perform controlling as well as switching operation using a remote control system. In this work, "Industrial Appliances Control Using Arduino Processor" through GSM is proposed and controlling a set of electrical appliances are achieved by setting up a remote control system using arduino boards. The objective of this work is to convert the manually operated plant to fully automated plant for achieving higher accuracy, efficiency and time saving.The GSM modem can provide the necessary information about load to an user located anywhere at any time. According to data received, user will take some action by sending some commands through mobile unit to GSM modem. Based on the command, the required appliance will be triggered. It can also be used for implementation of more complex systems. Which requires more precision controlling and switching for complicated tasks like controlling different systems in nuclear plant and reactors in the industry. It is used to reduce the maintenance costs and reduces human effort.
\end{abstract}

Keywords: GSM modem, DTMF decoder, Arduino processor

\section{Introduction}

Nowadays, in modern society this work is very useful if people can operate their domestic electrical appliances when they are away from them. The remote control system allows the user to interact with their appliances without touching them. This type of remote control system is more convenient and installisation process is simple. This new system can operate the wireless mode. The remote system is used to turn on or off the any combination of appliances with a control panel by your beside table, workstation, countertop or anywhere else.

\section{Benefits of Remote Control For Appliances}

- Facilitates wireless control over the equipment.

- Maintenance is easy and cost also effective.

- Ability to handle multi-channel function.

- Tamper proof and easy to portable.

The main objective of this work is to access remote control circuit for industrial appliances. In our project "Industrial Appliances Control Using Arduino Processor" we implemented a remote control for industrial appliances in cost effective manner.

A control system is a device, or combination of devices to manage, command, direct or regulate the behavior of other device(s) or system(s). Any system can be controlled in two different ways, either manual or automatic.

In control systems engineering, a system is actually a group of components. It can capable of performing individual tasks. They are connected in a specific sequence to perform a specific function. A system can be of two types and they are described below:

- Open loop system (Manual control system).
- Closed loop system (automatic control system).

\section{Literature Survey}

Cooperation between smartphone and home appliances becomes important and popular. Especially, smart phones equipped with Bluetooth4.0 can reduce the power consumption, increase connectable devices, and promote the cooperation between things and smart terminals. The typical devices are BLE, Fuel band (a pedometer developed by NIKE)[5], and BlueHR (a heartbeat meter developed by Wahoo Fitness).There is a need to use those technologies for controlling home appliances. On the other hand, in the smartphone application field, many applications for controlling home appliances have appeared by combining 3G and Wi-Fi technology. But they need a precondition that Available Internet.

The main purpose of this research is to develop an appliance control system without restriction of Internet. Moreover, we will build a dynamic control menu system, which can scan any appliance near a user for controlling at anywhere.

The main problems in this research include the development of Middle-Device and study of cooperation method between home appliances and smartphones using the Middle-Device. The problems can be described more concretely as, how to select devices, how to make communication between devices, and how to save operating data and home appliances information.

We adopt Arduino as the base of the Middle-Device, since the difficulty of operating the hardware is abstracted, programming is easy for a beginner, and the Arduino has more extensibility. The extension boards called "Shield" are attached, which is able to use the function of Ethernet, Zigbee, etc. 


\section{International Journal of Science and Research (IJSR) \\ ISSN (Online): 2319-7064}

Index Copernicus Value (2013): 6.14 | Impact Factor (2014): 5.611

\section{Methodology}

An implement and control of industrial appliances by using Dual Tone Multi Frequency in the help of Arduino processor. The proposed work block diagram is given below.

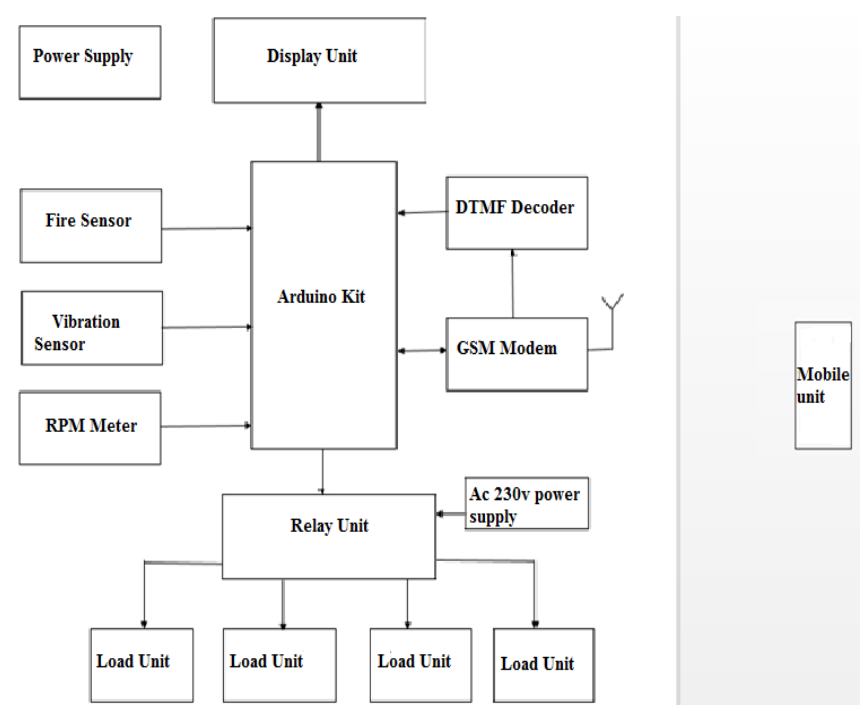

Figure 1: Block diagram of proposed method

\section{Relay}

A relay operation as same as switching operation. Mechanically switching mechanism is used in many relay operation, but it can use other operating principles. Relays are produced a low-power signal where it is necessary to control a circuit by or where one signal can be controlled the several circuits.

A relay is said to switch and it have a one or more poles. Each pole has contacts that can be connected in mainly three ways. They are

- Normally Open Contact (NO) - NO contact is known as make contact. If it is closes the circuit then the relay is activated. otherwise the relay is inactive.

- Normally Closed Contact (NC) - NC contact is called break contact. This is opposite to the NO contact. When the relay is ON state, the circuit disconnects. When the relay is OFF state, the circuit connects.

- Change-over (CO) / Double-throw (DT) Contacts - This type of contacts are used to control two types of circuits. They are used to control a NO contact and NC contact with a common terminal.

\section{DTMT Decoder}

The DTMF stands for "Dual Tone Multi-frequency" which is one of the techniques for converting the analogue signal to digital using DTMF decoder. This technology provides ultimate solutions for the telephone industries which is used to switch two lines automatically.

It is mostly used in mobile communications system which recognizes the sequence of DTMF tones from the standard keypad of the mobile phone.

\section{Fire Detection}

The flame occurrence is detected by using flame sensor. When the sensor detects the fire then it became short-circuit. otherwise sensor become open circuit.

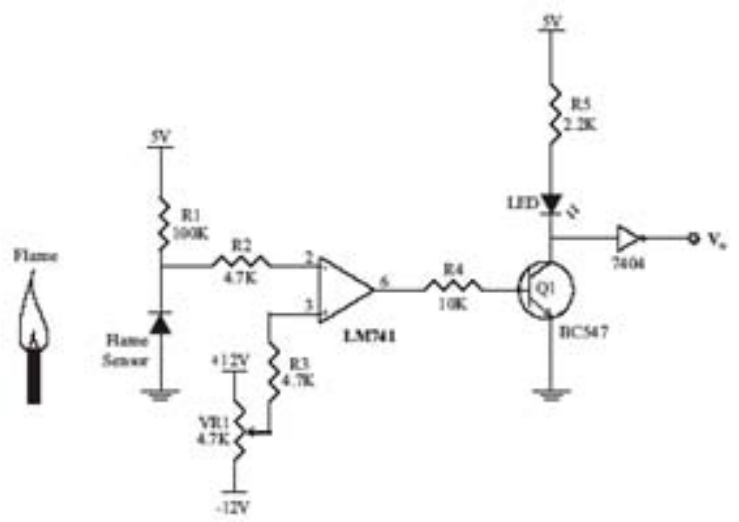

Figure 2: Fire detection circuit

\section{Circuit description}

The flame sensor is connected with resistor. Voltage divider network formed by the above connection after that which is connected with inverting input terminal of the comparator. The reference voltage is goes to non-inverting input terminal. LM 741 operational amplifier is used to make the comparator.

When there is no fire, the flame sensor became off mode. So the inverting input terminal voltage is greater than noninverting input terminal (reference voltage). Now the comparator output is $-12 \mathrm{~V}$ which is given to the base of the switching transistor BC547. So the transistor isn 't saturation region. It goes to cutoff region. The $5 \mathrm{v}$ is given to 7404 IC. It have the hex inverter with buffer. Hence zero voltage is given to microcontroller.

When there is fire occurred, the flame sensor became ON mode. So the inverting input terminal voltage is less than non-inverting input terminal. Now the comparator output is $+12 \mathrm{~V}$ which is given to the base of the switching transistor BC547. So the transistor is turned ON. The zero voltage is given to 7404 IC. Hence $+5 v$ voltage is given to microcontroller. In the microcontroller used to detect the fire with the help of software.

\section{Dc Motor Forward Reverse Control}

This circuit design used to control the motor in the forward and reverse direction. It have a two relays named as relay1, relay2. The pair of switching transistors are used to control the relay ON and OFF state. A Relay is nothing but electromagnetic switching device. It consists of three pins. They are Common, Normally close (NC) and normally open (NO). The two relay have a common pin that can be connected to positive and negative terminal of motor through snubber circuit respectively. The transistors T2 and T4collector terminals are connected to the relays.

When high pulse signal is given to either base of the T1 or $\mathrm{T} 3$ transistors, the transistor is conducting and shorts the 


\section{International Journal of Science and Research (IJSR) \\ ISSN (Online): 2319-7064 \\ Index Copernicus Value (2013): 6.14 | Impact Factor (2014): 5.611}

collector and emitter terminal and zero signals is given to base of the T2 or T4 transistor. So the relay is turned OFF state.

When low pulse is given to eitherT1 transistor or T3 transistor base terminals, the transistor is turned OFF. Now $12 \mathrm{v}$ is given to base of $\mathrm{T} 2$ or $\mathrm{T} 4$ transistor. therefore transistor goes to conducting state and relay will be turn ON. The NO and NC pins of two relays are interconnected so only one relay can be operated at a time.

The series combination of resistor and capacitor is known as snubber circuit. When the relay is turn ON and turn OFF continuously, the back emf may fault the relays. So the back emf is grounded through the snubber circuit.

- If relay 1 is in the ON state and relay 2 is in the OFF state, the motor is running in the forward direction.

- Otherwise if relay 2 is in the ON state and relay 1 is in the OFF state, the motor is running in the reverse direction.

Arduino have some special advantages are

- It is very Inexpensive compare to other technologies

- It is basically runs on Cross-platform application.

- It have aSimple, clear programming environment.

- It is an Open source and extensible software also available.

\section{Conclusion}

In this paper design and the implementation of an Industrial appliances control using arduino processor. The system has a user friendly interface and employs some techniques to reduce the power consumption. Communication of the system is complete wireless, which makes the system easy to install and use. The feature of this system is to adapt the appliances changes in different room. such as office, homes \& hotels. In addition, the wireless transceiver modules enable the system to transfer other information such as voice rather than just alarm signals. As a result, the system can slightly be expanded to other applications. It provides accurate results and also have noise reduction ability.Since it consists of feedback loop, it may create oscillatory response of the system and it also reduces the overall gain of the system.

\section{References}

[1] Basile F, Chiacchio P. and Gerbasio D. (2013), „On the implementation of industrial automation systems based


Vol. 10, No. 4, pp. 990 - 1003.

[2] Chore K, Deshpande S, Smitha P. and Vibhute S. (2014), „Home Automation Using PLC and SCADA ${ }^{c e}$ Multidisciplinary Journal of Research in Engineering and Technology, Volume 1, Issue 1.

[3] Fennibay D, Sen A. and Yurdaku A. (2012), „A heterogeneous simulation and modeling framework for automation systems, ${ }^{\text {e }}$ in IEEE Transactions on Computer-Aided Design of Integrated circuits and systems, Vol. 31, No. 11, pp. 1642 - 1655.

[4] Hanisch H .M. and Winkler H .L .T. (2011), ,A new model structure based synthesis approach for distributed discrete process control," in Proc, 9th IEEE int. Conf. Ind. Inf, Lisbon, Portugal, pp. 527 - 532.

[5] Hideki Matsuoka, Junbo Wang , Lei Jing, Yinghui Zhou, Yilang Wu and Zixue Cheng (2014), Development of A Control System for Home Appliances Based on BLE Technique $^{\text {ee }}$ IEEE Transactions on Consumer Electronics Univ.Aizu.

[6] Kshitij Mahajan, Omkar Deepak Gawde, Omkar Naik and Sanket Deshpande (2013), „Automation of Alloy Making Industrye International Journal of Computer Technology and Electronics Engineering (IJCTEE) Volume 3, Special Issue.

[7] Lwin Lwin Oo and Nang Kaythi Hlaing (2010), „Microcontroller-based single-phase automatic voltage regulator International Conference on Computer Science and Information Technology (ICCSIT), Chengdu, PP. 222 - 226.

[8] Valeriy Vyatkin I.S.M. (2013), ,Software engineering in industrial automation: State-of-the-art review, "e in IEEE, Transaction on industrial informatics, Vol. 9, No. 3, pp. $1234-1249$. 